\title{
Oral lichen planus: a microbiologist point of view
}

\author{
Tomás G. Villa ${ }^{1}$ (1) Ángeles Sánchez-Pérez ${ }^{2} \cdot$ Carmen Sieiro $^{3}$
}

Received: 17 November 2020 / Revised: 15 February 2021 / Accepted: 16 February 2021 / Published online: 10 March 2021

(C) Springer Nature Switzerland AG 2021

\begin{abstract}
Oral lichen planus (OLP) is a chronic disease of uncertain etiology, although it is generally considered as an immune-mediated disease that affects the mucous membranes and even the skin and nails. Over the years, this disease was attributed to a variety of causes, including different types of microorganisms. This review analyzes the present state of the art of the disease, from a microbiological point of view, while considering whether or not the possibility of a microbial origin for the disease can be supported. From the evidence presented here, OLP should be considered an immunological disease, as it was initially proposed, as opposed to an illness of microbiological origin. The different microorganisms so far described as putative disease-causing agents do not fulfill Koch's postulates; they are, actually, not the cause, but a result of the disease that provides the right circumstances for microbial colonization. This means that, at this stage, and unless new data becomes available, no microorganism can be envisaged as the causative agent of lichen planus.
\end{abstract}

Keywords Oral lichen planus $\cdot$ Origin $\cdot$ Bacteria $\cdot$ Fungi $\cdot$ Viruses $\cdot$ Immunodeficiency

\section{Introduction}

The disease known as "oral lichen planus" was originally described by Sir William James Erasmus Wilson in 1869 (for pathologic pictures of the illness, see Howell 1964). OLP is an inflammatory disorder of the skin and mucous membranes that, as is the case for other types of dermatitis affecting different occupational industrial groups (mainly in Germany, the UK, and, to a lesser extent, the USA), is regulated by workers' compensation laws and classified as an industrial disease (Schwartz 1933). It produces white lesions with a reticulated or plaque appearance (Bradley 1988); the

Tomás G. Villa

tomas.gonzalez@usc.es

Carmen Sieiro

mcsieiro@uvigo.es

Ángeles Sánchez-Pérez

angelines2085@icloud.com

1 Department of Microbiology, Faculty of Pharmacy, University of Santiago de Compostela, 15706 Santiago de Compostela, EU, Spain

2 Sydney School of Veterinary Science, Faculty of Science, University of Sydney, Camperdown, NSW 2006, Australia

3 Department of Functional Biology and Health Sciences, Microbiology Area, Faculty of Biology, University of Vigo, 36310 Vigo, Pontevedra, EU, Spain illness was recently classified, in clinical settings, into three subtypes (reticular, atrophic and ulcerative or erosive; Li et al. 2019a, b). However, as late as 2016, the disease was organized into six subtypes, according to its clinical expression; these include erosive, plaque type, papular, reticular, atrophic, and bullous (Cheng et al. 2016). In fact, earlier reports described as many as 11 clinical types of lichen planus; manifestations of the illness were described as papular, annular, linear, hypertrophic, actinic, ulcerative, pigmented, atrophic, bullous, follicular, or inverse (Wagner et al. 2013). Lichen planus atypicus (LPA) is a variety of the disease that mainly affects temperate regions of Earth. This affliction predominantly impacts tropical areas and presents as localized atrophic sequelae; it does not display the papules typical of the early phases, and the lesions are usually accompanied by hyperpigmentation, as indicated by Pointdexter in 1947.

\section{On the disease}

According to the World Health Organization, the disease can be considered as a premalignant condition and is also associated with immunodeficiency diseases (Peacock et al. 2017), but it only requires surgery, to prevent nasopharyngeal stenosis, in very severe erosive cases (Alastair et al. 2019). Gupta and Jawanda estimated in 2015 that lichen planus affects 0.5 
to $2.0 \%$ of the general population (only a fraction of it corresponds to OLP), it is most common in middle-aged females, and it may go undetected for long periods of time (Bornstein et al. 2008). The link between this disease and cancer was reported by Coussens and Werb in 2002, who associated two chronic inflammatory conditions (lichen planus and lichen sclerosus) with oral squamous cell carcinoma and vulvar squamous cell carcinoma, respectively, while Day and coworkers confirmed in 2018 the relationship between vulvovaginal lichen and squamous cell carcinoma. Lichen sclerosus is a rare disease that mainly affects prepubertal girls; it is also an autoimmune condition that can be triggered by Borrelia burgdorferi (Tomo et al. 2017), the etiological agent of Lyme disease. Chitturi et al. proposed in 2014 that the presence of aneuploid nuclei in the erosive forms of lichen planus was a good indicator of a premalignant state. In addition, Rao et al. reported in 2018 that the loss of heterozygosity in epithelial cells could predict the disease progression to carcinoma. Two publications (Matsuoka 1981; Horn et al. 1997) claimed microchimerism (described as the presence of a small number of foreign cells, originating from a genetically distinct individual, in the body; an example of naturally acquired microchimerism is pregnancy, as the fetal and maternal cells are genetically different) as a possible origin for OLP or lichenoid lesions. Nevertheless, Gammill and Nelson (2010) were unable to find a relationship between microchimerism and this type of disorders. In fact, these authors corroborated the findings by Bauer and co-workers, who stated in 2006: "Fetal microchimerism is not involved in the pathogenesis of lichen sclerosus of the vulva."

An additional factor, discussed by Yang et al. in 2014, is the role played by long non-coding RNAs and miRNAs, which regulate epigenetic mechanisms. The authors concentrated on a particular long non-coding RNA, Bic, involved in immune function; expression of this RNA is elevated in both activated $\mathrm{T}$ cells and in vulvar lichen planus (VLP). These results corroborate the earlier findings by Dang et al. (2013), who studied promoter methylation of the $\mathrm{p} 16$ gene, a tumor suppressor, and microRNA-137 (miR-137). They reported that, in both OLP and oral squamous cell carcinoma (OSCC), p16 and miR-137 promoters exhibited aberrant methylation. Based on this finding, the authors suggested that the methylation state of the promoters could be used as a biomarker for oral carcinogenesis. Sánchez-Siles et al. (2019) further investigated the influence of genetic aspects in OLP. They studied the promoter methylation of O16methylguanine-DNA methyltransferase (MGMT) $\mathrm{C}>\mathrm{T}$ alleles and reached the conclusion that the $\mathrm{T}$ variant (SNP; rs16906252) could represent an important feature in the clinical prognosis of premalignant lesions of OLP.

Salivary biomarkers could be of help in the differential diagnosis of lichen planus; one such example is the use of salivary exosomal microRNAs as an aid in OLP diagnosis, proposed by
Byun and colleagues in 2015. This idea was further developed by Kaczor-Urbanowicz and colleagues in their review in 2017; the authors suggested that saliva can be considered as a "mirror of the body" and would, hence, reflect the physiological and pathological changes occurring in the body. Of additional interest is the work by Talungchit and colleagues that, in 2018, instead of concentrating on RNA, investigated the proteins present in patients suffering from OLP. They described that at least 20 polypeptides were specific for those patients, with three proteins in particular, the complement fraction $\mathrm{C} 3 \mathrm{c}$, fibrinogen fragment $\mathrm{D}$ and cystatin $\mathrm{SA}$, selected as the most likely salivary biomarkers for OLP. That same year, Tampa et al. (2018) suggested additional biomarkers that could help diagnose the silent premalignant phase of the disease; these included modulators of apoptosis (p53, MCL-1), cell cycle regulators (BMI1, p16), tissue remodeling factors (MMPs), and inflammation-related factors (tumor necrosis factor alpha (TNF- $\alpha$ ), IL-6, and COX-2).

An alternative approach would be to monitor expression of tenascin- $\mathrm{C}$, the protein most studied in the tenascin family; this hexameric glycoprotein is composed of several extracellular matrix polypeptides and is found in both developing embryos and in some tumors. Tenascin-C expression would indicate that the lichen planus lesion has reached a premalignant state. Bandyopadhyay and co-workers revisited this subject in 2017 and concluded that a small percentage of OLP lesions would eventually evolve into oral tumors.

This disease, that in certain manifestations can be misdiagnosed as "yellow nail syndrome" (Haneke 1983), responds well to symptomatic treatment with corticoids, that are a very effective therapy even in esophageal forms of the illness (Sato et al. 2018). Additional treatments include daclatasvir/ asunaprevir (Nagao et al. 2016; Nagao et al. 2017), while the inflammation caused by the disease can be managed with green tea (Zhang and Zhou 2012), the carotenoid astaxanthin (Miyachi et al. 2015), photodynamic therapy (Mostafa and Tarakji 2015), topical application of hyaluronic acid at $0.2 \%$ (Shetty et al. 2016), or by inhibition of the enzyme phosphodiesterase- 4 . Inhibitors of this enzyme, such as roflumilast, apremilast and crisaborole (Li et al. 2018a, b), have already been approved for other diseases involving inflammatory reactions, including psoriatic arthritis and atopic dermatitis. Lichen planus can also be treated with di-rhamnolipids; these compounds, also known as BAC-3, are biosurfactants with anti-irritant effects produced by Pseudomonas aeruginosa (Stipcevic et al. 2005). In addition, Murakami and colleagues reported in 2012 that lichen planus can be controlled by melatonin, while recalcitrant lesions caused by the disease can be treated with calcineurin inhibitors, retinoids, or antimalarial drugs, such as the 4-aminoquinolines chloroquine and hydroxychloroquine or the acridine dye quinacrine (Kalia and Dutz 2007). Mester and colleagues suggested in 2018 that surgical intervention be recommended for isolated lesions. Treatment with interferon- $\alpha$ can aggravate lichen planus lesions, in particular in patients undergoing hepatitis $\mathrm{C}$ treatment. Less 
aggressive treatments include the use of a $\beta$-D-pyranoid polysaccharide from Angelica sinensis that displays a variety of properties, including antitumor activity and protection against radiation (Wang et al. 2016a, b; Li et al. 2018a, b; Wang et al. 2019).

Lichen planus is a chronic disease with an uncertain etiology; it was originally suggested that it involved a microbial infection of the nervous system (an idea that prevailed for over 120 years), and has also been associated with diets poor in retinol and beta carotene (Scardina and Messina 2012). What is currently clear is that the human immune system is definitively involved, generating inflammatory responses in the oral cavity, hair, nails, and mucous membranes (Gorouhi et al. 2014; Cheng et al. 2016). A variant of the disease, known as "lichen planus pigmentosus-inversus," rarely found in Caucasian populations, is characterized by brown spots on cervical, axillary, inguinal, and popliteal regions (Pock et al. 2001; Barros et al. 2013).

The classical form of the disease belongs in the group of most common cutaneous disorders, together with lupus erythematosus, pemphigus, and erythema multiforme. It occasionally develops in people suffering from diabetes mellitus (Negrato and Tarzia 2010), or following treatment with certain drugs, such as chloroquine (Branch et al. 1948). This illness can produce strange pleiotropic effects; one such example is reported by Sahin and co-workers in 2013, who described that lichen planus could significantly affect the $\mathrm{P}$ wave dispersion on electrocardiograms, as well as raising the overall levels of C-reactive protein, LDL cholesterol and triglycerides.

The disease occurs mainly in the oral mucosa, but it can also develop in the female vagina (Machin et al. 2010), where it is often missed or misdiagnosed. The authors reported that the vaginal manifestation can progress rapidly, increasing morbidity and affecting sexual function; if left untreated, it can produce adhesions that completely occlude the vagina, requiring surgery.

In all its manifestations, lichen planus is accompanied by an increase in mast cell counts, as reported by Sharma and colleagues in 2011; this is an important fact, as mast cells have extremely long life spans, involving weeks or even months, and lichen planus is a long-term disease. The involvement of mast cells in this illness was already glimpsed by Walsh et al. in 1995, as they described TNF- $\alpha$ as one of the bioactive molecules present, and mast cells are a major cellular source of this pro-inflammatory cytokine.

In addition, genes associated with altered autophagy (IGF1, ATG9B, HGS, ESR1, and SNCA) were shown to correlate well with OLP (Tan et al. 2016).

Rapid prediagnosis of this disease is therefore a must, and research has been carried out in this field for many years; this has resulted in the identification of a variety of biomarkers, described above, that are useful in the diagnosis of this disorder. The studies also identified a variety of polypeptides, such as salivary endothelin-1, which cannot be used in disease diagnosis (Cheng and co-workers set the issue in 2011). The 70-kDa heat shock protein Hsp70, also known as DnaK, is a molecular chaperon involved in protein folding, as well as stress protection, produced by multitude of cell types (Tavaria et al. 1996). Seoane and co-workers investigated in 2004 the involvement of Hsp70 in OLP and non-dysplastic oral leukoplakia; although the authors reported that expression of the heat shock protein was considerably higher in oral leukoplakia than in lichen planus, it was later established by Tyagi et al. (2012) that this molecular chaperone is overexpressed in lichen planus, confirming the involvement of the protein in the onset and progress of the disease, thus validating Hsp70 as a lichen planus biomarker.

Although the disorder is generally believed to be caused by an autoimmune reaction, many researchers maintain that a microbial infection triggers the autoimmune response (Choi et al. 2016; Mizuki et al. 2017). The term "lichen" refers to the shape of the lesions that appear on the body surface, that resemble a flat lichen. As indicated above, treatment with certain drugs has also been implicated as possible cause of this disorder, at least in certain manifestations of the disease, such as LPA. In fact, Poindexter suggested in 1947 the drug atabrine (used to treat malaria in endemic regions) as a possible cause of the disease. LPA was described to produce several types of lesions; a "pruritus ani" described by Brossy in 1955 displayed lesions of different shapes that involved annular (ring-shaped), papular (shiny, red- or purple-colored, flattopped papulae (this is the classical shape), linear, and bullous (forming vesicles). The OLP disease can be mistaken for lupus erythematosus, although this autoimmune syndrome, in addition to the skin, can affect joints, kidneys and lungs. Lichen planus (LP) is characterized by lesions with perivascular accumulation of mononuclear cells, although this is also the case for parapsoriasis and toxic erythema (Allen and Spitz 1945).

OLP, as indicated above, is thought to involve a T cellmediated response $\left(\mathrm{CD}^{+}\right)$with the lesions, in fact, resulting from a cytotoxic reaction against epithelial basal cells (Roopashree et al. 2010). The pathological process involves TNF- $\alpha$ secretion (Carrozzo et al. 2004) and keratinocyte apoptosis (also observed in pemphigus foliaceus; Li et al. 2009), as well as chemokine secretion that, in turn, attracts more proinflammatory cells to the lesion, resulting in chronic inflammation. Xavier and colleagues conducted in 2007 a series of studies on functional gene polymorphisms, affecting interleukin- $1 \beta$, interleukin- 6 , interleukin- 10 , and TNF, in patients suffering from LP; they were able to establish an association between IL- 6 and TNF- $\alpha$ polymorphisms and the disease, confirming a genetic basis for the disorder. This genetic link was further confirmed by Chen et al. who, in 2013, demonstrated that two cytokines, interleukin-22 and interleukin-23, were involved in the development of lesions in both oral and cutaneous lichen planus; a higher percentage of cells 
expressed these cytokines in lesions, as compared to the healthy controls. Adami et al. corroborated these findings in 2014, documenting an additional four genes that are overexpressed in OLP; the upregulated cytokines are IL-8 (interleukin-8) and TLR-1 (Toll-like receptor 1) and, to a lesser extent, CD14 (monocyte differentiation antigen) and CXCL1 (melanoma growth-stimulating activity, alpha).

Interleukin-17 was also described to be elevated in LP (Ge et al. 2020); the higher titer of this particular interleukin is mediated by the action of renin, that promotes STAT4 phosphorylation which, in turn, induces production of the cytokine in keratinocytes.

Do et al. reported in 2018 that the elevated OGlcNAcylation found in LP is associated with increased expression of the NLRP3 inflammasome, via the NF-KB signaling pathway. This type of glycosylation, added onto serine or threonine, is not as common as N-glycosylation; it involves a di-N-acetyl-chitobiose bridge and could represent an additional biomarker in the diagnosis of LP.

Interferon gamma was also proposed to play a role in this disease, provided that there is enough amount of this lipoprotein in the skin (Jiang et al. 1994); it activates keratin K7 synthesis through nuclear translocation of STAT-91. These results were later corroborated by Malekzadeh and colleagues, in 2015; the authors described that both salivary interferon gamma and interleukin-4 were elevated in patients suffering from LP. In addition, the levels of differentiation-specific keratins (K4, $\mathrm{K} 13$, K1, and K10) were also elevated in oral non-dysplastic keratosis, including LP. Bloor and colleagues had already described in 2000 that the synthesis of K1 and K10 was upregulated in those skin conditions, and that the expression pattern of differentiation-specific keratins was altered in LP.

Oncogenic viruses were also detected in lesions, in particular human papillomaviruses types 16 and 19; these viruses form a complex between the viral protein E6 and the cellular tumor suppressor $\mathrm{p} 53$ (Loning et al. 1985), hence reducing the activity of the tumor suppressor protein and creating a cellular preoncogenic state (Burns et al. 1994). The situation is further assisted by infiltrating $\mathrm{CD} 8^{+} \mathrm{T}$ cells, that express mainly CCR5 and CXCR3 (functional chemokine receptors) and carry the chemokine ligands RANTES/CCL5 and IP-10/ CXCL10 (Lijima et al. 2003).

TLRs are a family of proteins (10 in the case of humans, that can even be found in saliva; Zunt et al. 2009) involved in pattern recognition, since they play a role in the identification of the normal commensal microbiota. TLR-2 and TLR-4 recognize bacterial lipopolysaccharides, peptidoglycans and lipoproteins (Akira and Takeda 2004; Ren et al. 2005), whereas TRL-9 identifies bacterial nucleic acids (Kawai and Akira 2010). Toll-like receptors (such as TRL-2, TRL-4 and TRL9) have been unambiguously associated with the onset of OLP (Mori et al. 2003; Siponen et al. 2012). It has also been suggested that nucleotide-binding oligomerization domain proteins, such as NOD1 and NOD2 (NOD1 exhibits caspase activation and recruitment domains, while NOD2 contains the caspase recruitment domain 15, also found in Crohn's disease), could be involved in the development of OLP and similar disorders affecting the oral epithelium (Sugawara et al. 2006). In fact, in 2008, Uehara reported a synergism between TLRs and NOD1/2 in oral epithelial cells. Activation of TLR2, TLR4, NOD1, and NOD2 affects the periodontal ligament fibroblasts, which play a crucial role in protecting the periapical tissue; if this safeguard is lost, pathogenic bacteria can colonize the niche, causing deleterious effects (Tang et al. 2011).

To complicate matters even more, there is increasing evidence that endothelial dysfunction, and its concomitant aberrant angiogenesis, plays a role in the pathogenesis of OLP (Mittal et al. 2012). In addition, the Forkhead box P3 (FoxP3) protein, a transcription factor belonging to the forkhead family produced by thymus-derived cells such as regulatory $\mathrm{T}$ cells (Tregs), is also involved in two forms of OLP (reticular and erosive), according to Pereira et al. (2012). The authors described an increase in the number of FoxP3 ${ }^{+}$ cells in the erosive form of the disease and correlated these additional cells with the microbiota alteration present in the patients, particularly in people suffering from erosive OLP. Epithelial Langerhans cells also play an active role in the disease, since they are involved in antigen detection and capture, as well as subsequent presentation to T cells (Kulkarni et al. 2016).

Despite all the knowledge accumulated, the cause of the disease still remains unclear to many researchers; hence, medical practitioners usually carry out a differential diagnosis, eliminating conditions such as psoriasis, cicatricial pemphigoid, graft-versus-host disease, oral squamous cell carcinoma, leukoplakia buccalis, and oropharyngeal candidiasis, even including the rare yellow nail syndrome. It appears that the human genetic background is not sufficient to develop OLP, and onset of the disease requires the interaction of the human mucosa with particular microorganisms (Fig. 1). When highly evolved eukaryotic cells, such as epithelial cells, interact with stimuli such as bacteria, viruses (such as the human herpes virus 7 or the hepatitis C virus; de Vries et al. 2007; Ghodsi et al. 2004, respectively), fungi, or exosomal miRNAs, the cells express antibacterial peptides, such as $\beta$-defensins (potent antimicrobial peptides produced by epithelial cells; Ageitos et al. 2017); this usually stops the infection at an early stage, protecting underlying parts of the body (Salem et al. 2019). As it is well known, the human skin is formed by three layers; the epidermis is the first layer and constitutes a physical barrier that contains keratinized cells and specialized dendritic cells (Langerhans cells). The second layer, or dermis, involves connective tissue, dermal dendritic cells (DCs), mast cells, and memory T cells, while the third layer, the subcutaneous layer, contains low levels of E-selectin, CC chemokine 


\section{Bacteria}

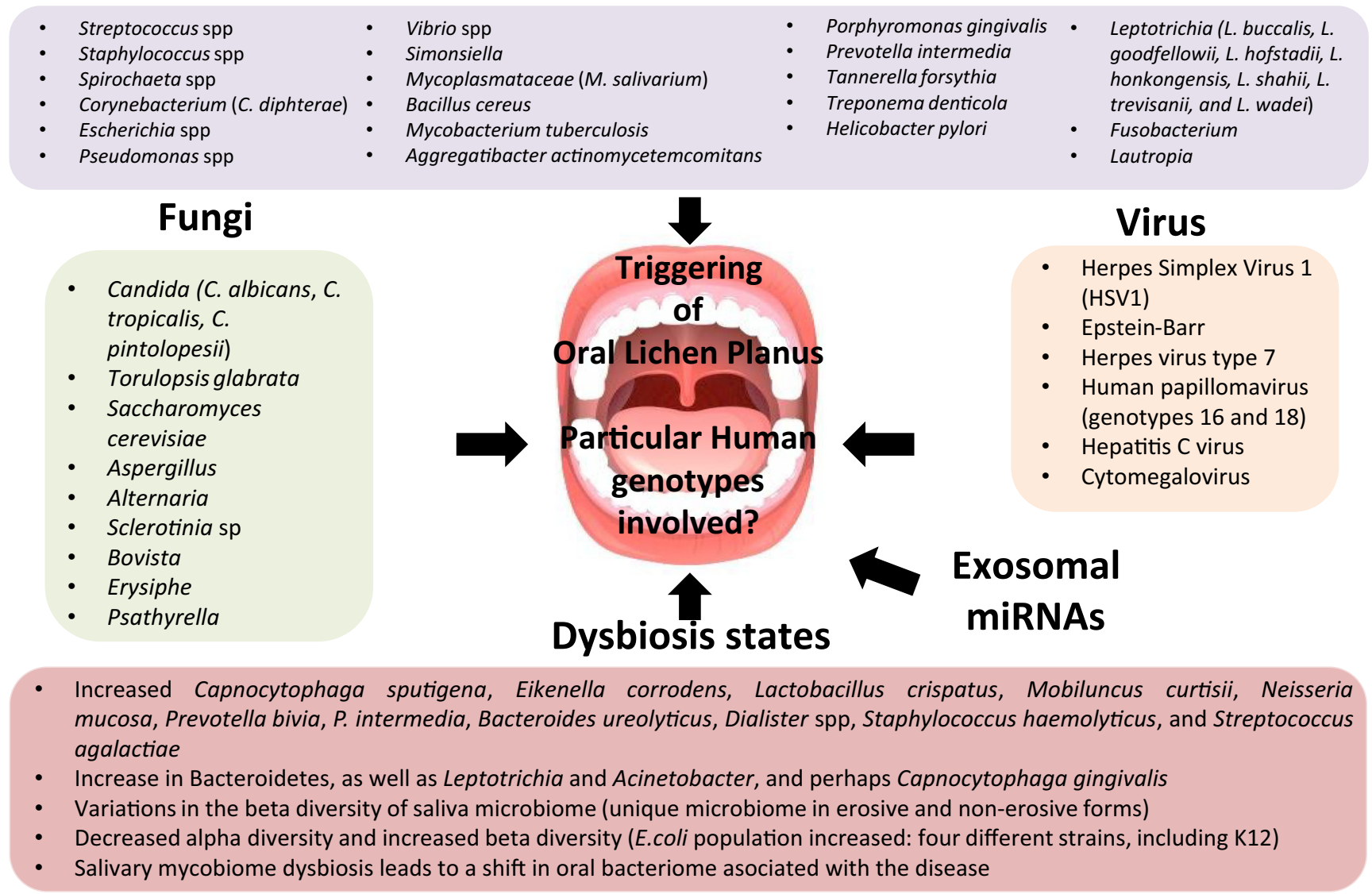

Fig. 1 Possible microbial origin of oral lichen planus

ligand 17 and intercellular adhesion molecule 1 (Kupper and Fuhlbrigge 2004). If any of the three skin layers are affected, and the person has the right genetic background, OLP can develop.

According to Irvine (1991), LP can be considered as a case of "skin failure," where autoimmune reactions create an environment that allows different microorganisms to colonize it. The author suggests a possible cause for this failure: "loss of normal temperature control with inability to maintain the core temperature, failure to prevent percutaneous loss of fluid, electrolytes and proteins with resulting imbalance and failure of the mechanical barrier to penetration by foreign materials."

\section{Bacteria associated with oral lichen planus}

After the original description of the disease, by Erasmus Wilson, the use of the term "lichen planus" was supported by Dr. Unna in 1896, describing it as preferable to some of the other names used to describe the illness, such as "ruber" or even "hebra" (after Ferdinand Ritter von Hebra, the founder of the New Vienna School of Dermatology, in AustriaHungary), which were causing confusion among medical practitioners. Although Unna did not clearly state the association of the disease with a particular microorganism, his publications provided an inkling on this possibility, since the disease was quickly cured upon treatment with quicksilver (this aspect was later further explored by de Forest in 1923). Two years later, Fox (1898) used the term LP to refer to a particular syndrome in the skin of children, but nothing was mentioned about the presence of microorganisms. One of the first reports associating bacteria with this disease is provided by Lederer; this author, in 1919, described the prophylactic use of commercial typhoid or typhoid-paratyphoid vaccines in the treatment of the disease, although the article did not provide any information on the cause of the illness. Finally, in 1922, Leslie-Roberts established a link between oral bacteria and OLP; he described the case of a female patient with extensive advanced pyorrhea, who was cured of the disease by having all her infected teeth removed. But, again, the responsible bacteria were not identified; in fact, although a variety of bacteria had already been described in 1924, the etiology of OLP still remained unknown. However, the controversy about this illness remained for several years, as the disease appeared to be refractile to treatment by UV light (Riddell 1928) and many practitioners attributed this condition to a variety of 
factors, including the patient's diet (i.e., Bray 1933). Eventually, in 1936, Brain confirmed the presence of streptococci and staphylococci in the lesions of a 9-year-old girl suffering from LP; in fact, Brain even hypothesized that a virus could be involved. It must be noted that, at the time, it was well understood the clinical significance of $\beta$-hemolytic streptococci; as reported by Mitchell in 1935, "the Streptococcus is there for business and not as an innocent bystander"; Souter 1937).

Poindexter (1947) described the microorganisms that had already been isolated and identified from syndromes similar to LP, such as "jungle rot"; these include pyogenic cocci, necrotizing staphylococci, spirochetes, fusiform bacilli, Corynebacteria (including Corynebacterium diphtheriae) and several Gram-negative rods (including Escherichia, Pseudomonas and Vibrio).

It was, therefore, generally believed by both the medical practitioners and microbiologists alike, at a time when immunology was still in its infancy, that the skin lesions known as LP (including all of the clinical types of the disease) were probably the result of bacterial infection. At that point in time, it was already known that certain bacteria, such as Streptococcus pyogenes, Staphylococcus aureus and, obviously, C. diphtheriae, produced dangerous toxins; hence, it was important (and indeed recommended) to precisely identify the microorganism responsible for the OLP, as well as to provide the appropriate antimicrobial treatment for the disease. It also became apparent later on that the skin injury could facilitate colonization by additional bacteria, as well as viruses; the ubiquitous herpes simplex virus 1 (HSV1) was identified as one of the most common viruses colonizing the skin lesions, generating a condition known as eczema herpetiform or Kaposi varicelliform eruption (Barrow 1954).

To celebrate 100 years since the description of LP by Wilson (1869), the British Medical Journal produced an editorial note (1969) that described the same possible causes of the disease as those reported many years earlier, while still maintaining a microbial origin or a nervous etiology for the disease; this is just an indication of how evasive the etiology of this illness has been. The two origins described for OLP were based on the limited knowledge available; the microbial origin is based on the findings from skin biopsies, which were interpreted as bacteria or aggregations of viral particles, whereas the nervous origin arose from the belief that emotional stress could trigger the disease (Samman 1969). In addition, the above theories were supported by a number of studies (such as that of Fry and Withers in 1968) that reported the failure to cultivate either viruses or mycoplasma from OLP lesions.

It was not until 1984 that Carandina and co-workers managed to isolate a bacterium, identified as belonging to the genus Simonsiella, from an OLP lesion in a 58-year-old woman; until then, the microorganism was considered as a transient, and harmless, inhabitant of the human oral cavity. Two years later, Watanabe et al. (1986) discovered a species belonging to the family Mycoplasmataceae (Mycoplasma salivarium) associated with certain lichen planus lesions; to the best of our knowledge, these two cases represent the first occasions in which an "unusual" bacterium was considered as the trigger for this disease. In fact, Mizuki and co-workers, in 2017, also isolated Mycoplasma salivarium from an OLP lesion, they immunohistochemically identified and intracellularly located the microorganism in epithelial cells; the authors emphasized that the bacterium is not present in the epithelium of healthy people (Mizuki et al. 2017).

It is well established that the human oral and vaginal normal microbiome can include anaerobic bacteria, even species belonging to the order Methanomicrobiales, in particular the archaeal Methanobrevibacter smithii (Belay et al. 1990), but there are no reports indicating that this microorganism is associated with OLP.

Variations in the normal microbiota can lead to LP; this was confirmed by Bornstein and colleagues in 2008, who found significant variations in the number of bacteria in patients affected by the reticular form of LP, although all of them displayed an elevated number of Treg cells. The bacterial populations displaying an increased proliferation in different forms of the disease were Capnocytophaga sputigena, Eikenella corrodens, Lactobacillus crispatus, Mobiluncus curtisii, Neisseria mucosa, Prevotella bivia, P. intermedia, Bacteroides ureolyticus, Dialister spp., Staphylococcus haemolyticus, and Streptococcus agalactiae (Lundgren et al. 2003). Additional studies confirmed the correlation between the disease and oral microbial dysbiosis (Baek and Choi 2018; Baek et al. 2020). More recently, Yu et al. (2020) revisited the subject of saliva microbiome dysbiosis in patients affected by OLP; the authors described that the beta diversity of the microbiome varied in different clinical forms of the disease, with their results indicating that the microbiomes may be unique and different in the two manifestations of the disease, erosive and non-erosive. It must be noted here that the dysbiosis caused by the presence of Pseudomonas aeruginosa in the oral cavity, which causes an increase in the concentration of nitric oxide (NO), is believed to be one of the leading causes of oral squamous cell carcinoma (Kakabadze et al. 2020).

Bacillus cereus was also isolated from the oral erosions caused by this disease; the peculiarity is that, although the bacterial strains known to be involved in other oral diseases lack the S-layer (surface layer present in many bacteria), the particular strain involved in the etiology of OLP does contain an S-layer (Auger et al. 2009).

The Mycobacterium species usually associated with skin lesions are M. leprae, M. bovis and the Bacillus CalmetteGuérin (Frankel et al. 2009), while M. tuberculosis rarely affects the skin. Nevertheless, Gharabaghi reported in 2012 a case of "cutaneous tuberculosis," caused by an isoniazidresistant strain of this bacterium, but no association between 
Mycobacterium and LP has ever been established. Nevertheless, 6 years earlier, Erbagci et al. (2006) described that a patient suffering from tuberculosis verrucosa cutis, as well as long-standing generalized LP, recovered from both diseases following antitubercular polychemotherapy (isoniazid, rifampicin, ethambutol, and pyrazinamide); this result suggests that a Mycobacterium species (probably tuberculosis) could be involved in the onset of OLP.

In 2013, Ertugrul and colleagues observed that OLP patients were more likely to suffer from infections by Aggregatibacter actinomycetemcomitans, Porphyromonas gingivalis, Prevotella intermedia, Tannerella forsythia, and Treponema denticola, as compared to people not affected by the disease; the conclusion was that all these bacterial species can be involved in periodontal diseases. More recently, Wang et al. (2018) reported that $P$. gingivalis lipopolysaccharide (LPS) somehow affected fibroblasts in OLP patients, and the cells acquired myofibroblastic characteristics, thus secreting pro-inflammatory cytokines.

The gastrointestinal pathogen Helicobacter pylori is often identified in people suffering from OLP (KazanowskaDygdała et al. 2016), but only in $23 \%$ of the patients; as this is not the case for healthy people, who do not appear to harbor H. pylori DNA, it can be deducted that this bacterium does not trigger the disease, but represents a secondary colonizer which presence is facilitated by the development of the disease.

Non-motile facultative anaerobic oral bacteria, and in particular species belonging to the genus Leptotrichia, have also been described as involved in triggering OLP (Emenike and Olsen 2017). A number of these bacteria (L. buccalis, L. goodfellowii, L. hofstadii, L. honkongensis, L. shahii, $L$. trevisanii, and $L$. wadei) produce lactic acid and represent opportunistic pathogens, including strains that cause septicemia. These findings were already reported by $\mathrm{He}$ and coworkers in 2017; in addition to Leptotrichia, they also described Fusobacterium and Lautropia as playing a role in OLP, although some differences were observed between the erosive and non-erosive manifestations of the disease.

A recent report by Li et al. (2019a, b) described that salivary mycobiome dysbiosis (i.e., lower saliva mycobiome biodiversity and higher bacterial biodiversity) plays a role in OLP; changes in oral bacterial composition can affect the host immunity and contribute to the pathogenesis of the disease. In fact, 3 years earlier, Wang et al. (2016a, b) produced a preliminary analysis of the salivary microbiome and its involvement in the disease, and Baek and Choi reported in 2018 that a microbial infection was the cause of OLP.

Once the microbial infection theory was developed, a variety of bacteria were postulated to trigger the onset of LP. The disease alters the composition of the microbial community and the human immune system responds by synthesizing a variety of peptides with antibacterial activity. In addition to the most commonly known antimicrobial peptides, such as the $\alpha$ - and $\beta$-defensins and histatins, the mature form of cathelicidin hCAP-18, known as LL-37, is believed to be also involved in OLP. The people suffering from this condition exhibited higher levels of cathelicidin than the healthy population, and there was a direct correlation between the severity of the disease and the amount of the peptide produced; Davidopoulou et al. (2014) concluded that LL-37 may protect against the pathogenic bacteria and facilitate wound healing.

In 2013, Marttila and co-workers described that the microbiota recovered from people suffering from lichenoid disease (an illness that produces lesions similar to those of LP or carcinoma) produced significantly higher levels of acetaldehyde (in fact, levels so high that were considered carcinogenic), as compared to healthy individuals.

The publication by Choi and colleagues in 2016, although referred to above, merits another citation here; the authors not only gave an appropriate description of the microbiota variation during OLP, but they also reported the internalization of selected bacterial species into human oral epithelial cells, as well as into leukocytes. The latter is of particular relevance on account of the role this internalization plays on both cytokine induction and the invasion of the lamina propria; accordingly, the authors described a significant increase in the population of bacteria such as Bacteroidetes, Leptotrichia and Acinetobacter, and perhaps also Capnocytophaga gingivalis, as indicated above.

The Human Microbiome Project (HMP) was established in 2008 and described as: "A strategy to understand the microbial components of the human genetic and metabolic landscape and how they contribute to normal physiology and predisposition to disease." It is essential to understand not only the gut microbiome, but also the microorganisms that are harbored by the nasal, vaginal, oral, and skin microenvironments. The oral microbiome is of particular interest in order to understand (1) if bacteria are really responsible for triggering OLP and (2) which bacterial species, if any, are involved. This Project has already confirmed correlations between particular alterations in the normal human microbiome and certain diseases (Kundu et al. 2017; Schmidt et al. 2018; Xian et al. 2018); they include illnesses affecting the digestive system, cardiovascular diseases and even some types of tumors.

In 2020, Baek and co-workers characterized the intratissue bacterial communities present in OLP lesions, by highthroughput sequencing of the microbial 16S rRNA genes. The authors discovered an intriguing fact, as they described a decreased alpha diversity and increased beta diversity in the bacterial populations, as compared to normal microbiota; in addition, they found an increase in the Escherichia coli population present, with the isolation of four different strains, including K12. This diversity in the number of $E$. coli strains identified in OLP lesions led the authors to suggest a role for this bacterial species in the genesis of the disease. 
It is most likely that, in addition to dysbiosis in the oral microbiota, dysbiosis in the gut microbiota would also play a role in OLP. Changes in the composition and function of the microbiota in the skin and gut have been linked to the development of some immune-mediated skin diseases (IMDs), such as psoriasis or atopic dermatitis, supporting the data emerging on the existence of a gut-skin axis (Eppinga et al. 2016; Lee et al. 2018). Dysbiosis of the gut microbiota causes the disruption in the integrity of the intestinal barrier, with the consequent increase in gut permeability ("leaky gut"); this allows the entry of microorganisms and toxins into the circulatory system that can, thus, reach other target organs, including the skin. The result of this is a combination of systemic and local inflammation, which contributes to skin diseases. People afflicted by either atopic dermatitis (Song et al. 2016) or psoriasis (Eppinga et al. 2016) suffer from gut dysbiosis that involves a reduction in the microorganism Faecalibacterium prausnitzii spp., as compared to healthy individuals; it is important to note that this bacterium stimulates the production of short-chain fatty acids with anti-inflammatory activity.

Despite all the advances in recent years, there is still no consensus as to what type of bacteria causes OLP; there are probably a number of microorganisms involved, or perhaps bacteria are not responsible for this disease, as the criteria for establishing the bacterial origin of a disease are not fulfilled. These criteria, summarized in Koch's postulates, are the gold standard for microbiologists and epidemiologists. An additional fact that supports that this illness is not caused by bacteria is the fact that it is not contagious, despite an early report by Corsi (1947) suggesting an example of contagion.

\section{Fungi associated with oral lichen planus}

Poindexter (1947) was one of the first researchers to report the presence of fungi in "jungle rot," a syndrome similar to LP; he lists a variety of fungi, including Epidermophyton inguinale, Trichophyton gypseum, T. interdigitale, T. purpureum, Candida albicans, Cryptococcus hominis, Oidium pulmoneum, and $O$. dermatitidis. But to be able to determine what type fungi (if any) is involved, or associated, with OLP, the "normal mycobiome," present in healthy humans, needs to be identified. This constitutes a difficult task, as the human mouth is a septic cavity that includes fungi, bacteria, protozoa, and all kinds of viruses (Ghannoum et al. 2010; Villa et al. 2016). In fact, the microbial diversity in the buccal cavity is only second to the intestinal microbiota, with this microbial proliferation resulting in human bites having a high rate of infection. Ghannoum et al. (2010) described 74 cultivable and 11 non-cultivable fungal genera found in the oral cavity as part of the buccal normal mycobiome. These microorganisms include a variety of known pathogenic fungi, with Candida species isolated in as many as $75 \%$ of the healthy volunteers, tested followed by fungal strains belonging to genera such as Cladosporium, Aureobasidium, Saccharomycetales, Aspergillus, Fusarium, and Cryptococcus.

Panja (1925) was one of the first researchers to report the presence of fungi in a variety of lichen known as "lichen spinulosus"; this disease, although similar to OLP, displays a clear cellular hypertrophy around the hair follicles. A more recent report, by Hongal and colleagues in 2015, described the presence of fungal hyphae in $\sim 36 \%$ of patients with premalignant lesions of OLP; the authors concluded that the presence of the fungi could be considered as a useful predictor for possible malignant transformation of the lesions. In fact, reports on fungi associated with OLP have been rare. In addition, Fox and Ainsworth carried out a fairly large study in 1958 and reported that in a variety of diseases, including OLP, lupus erythematosus disseminatus, leukoplakia, fungating antrum carcinoma, and dry socket, there was no significant variation in the buccal fungal population. In contrast, Odds et al. described in 1989 that the yeast $C$. albicans is unequivocally associated with OLP in $37 \%$ of the patients; the authors also reported that, apart from C. albicans (Jacobsen et al. 2008), there were additional yeast species occasionally present in the lesions, including $C$. tropicalis, $C$. pintolopesii, Torulopsis glabrata, and Saccharomyces cerevisiae. However, a more recent study (Hong et al. 2020) indicated that the presence of $C$. albicans in OLP lesions is not as common as previously believed, reporting a prevalence of only 18.87 and $18.75 \%$ in non-erosive and erosive varieties of the disease, respectively, while the prevalence of the yeast is $7.92 \%$ in healthy people. The conclusions from the latter report indicate that although the disease appears to involve only a minor dysbiosis, at least concerning $C$. albicans, the yeast only appears in a small percentage of people suffering from OLP; this suggests a role for the pathogenic yeast as a secondary colonizer, as it does not fulfill the conditions reflected in Koch's postulates to be considered as the origin of the disease. In addition to this yeast species, filamentous fungi have also been associated with OLP; Li and colleagues reported in 2019 the presence of Aspergillus in lesions from patients suffering from the reticular clinical form of the disease, while Alternaria and Sclerotinia spp. were recovered from people with erosive OLP. An interesting fact described by these authors is that there is a positive correlation between fungal genera, such as Bovista, Erysiphe and Psathyrella, and interleukin-17 levels. Both unicellular and filamentous fungi can be easily visualized in saliva by direct staining with calcofluor white, thus facilitating the fungal diagnosis; this compound binds both chitin and 1,3- $\beta$-D-glucan present in fungal cell walls, although the intensity of the fluorescence is lower in the case of the latter (Benitez et al. 1976; Punjabi et al. 2020).

As shown above, there is a considerable fungal diversity in the human mouth, which not only gradually changes with age, but is also different in men and women, hence probably 
influenced by sex hormones. It was originally believed that the human mycobiome was limited to just a few species, including C. albicans and perhaps C. parapsilosis, but this was only due to the lack of appropriate culture media that limited the number of fungal species that could be cultivated in the laboratory. The use of molecular biology methods, such as PCR, that overcame many of the difficulties previously encountered, demonstrated that there are, indeed, a great variety of fungi that integrate the human microbiome; these include, in addition to those reported above, genera such as Penicillium, Geotrichum and Hemispora. In summary, it appears that the fungal growth present in OLP lesions is the effect, and not the cause, of the disease, as is the case for bacteria. The colonization and proliferation of fungal species in lesions is facilitated by the metabolic imbalance in the affected epithelial cells, involving the release of cytokines, as well as the availability of nutrients, originating from human cells lysed in the disease process.

\section{Viruses associated with oral lichen planus}

As early as 1936 , Brain reported the possibility that viruses could be the cause of certain tumors; this included the formation of skin pseudotumors associated with viral diseases as well as the origin of certain skin diseases such as LP (Corsi 1947). This subject, however, did not receive much attention in the following years, but the idea of viruses causing diseases gained momentum as clinicians investigated the origin of skin diseases (including the mucosa), in which particular types of viruses appeared to be involved. The interest in this subject grew stronger in the 1980s, with the appearance of the human immunodeficiency virus (HIV); numerous cases of HIV infection involved the development of skin tumors, until then rarely encountered in clinics. One virus strongly associated with HIV is human herpes virus 8, which causes Kaposi's sarcoma tumors, that often require differential diagnosis to determine the tumor stages; in fact, dermatitis is one of the most common symptoms caused by the development of HIV (Epstein and Mathias 1988). In addition, HIV treatments with a variety of compounds, such as the HIV protease inhibitors or reverse transcriptase nucleoside inhibitors, often generate mucosal alterations, due to their interference with cell differentiation and proliferation of primary gingival epithelium (Israr et al. 2010; Israr et al. 2011; Mitchell et al. 2012).

Human saliva is an exocrine secretion, not only in humans but also in other mammals, that is rich in viruses; according to Slots and Slots (2011), saliva can contain viral particles from a variety of viruses, such as papillomavirus, immunodeficiency virus, T cell lymphotropic virus type I, hepatitis viruses $\mathrm{A}, \mathrm{B}$, $\mathrm{C}$, and $\mathrm{G}$, respiratory syncytial virus, parainfluenza virus, influenza virus, adenovirus, severe acute respiratory syndrome coronavirus, Merkel cell carcinoma virus (a polyomavirus), and BK polyomavirus. These viruses can eventually cause cancerous tumors, in both humans and other animals, and can remain in human bodies for a long time, as described by Slots and Slots in 2011. Of particular concern are papillomaviruses, that can produce a variety of cancers, including cervical, anal, vulvar, vaginal, and penile cancers.

Human papillomavirus (HPV) is a DNA virus that can cause a variety of both cancerous and benign tumors. Maitland and co-workers reported in 1987 the presence of the virus in a high percentage of patients affected by OLP; although HPV was also found in healthy people, as well as in persons with oral tumors, the percentage of healthy people infected by the virus was much lower. Razavi and colleagues were among the first researchers to investigate the possibility that human papillomavirus was the cause of OLP (Razavi et al. 2009), but they rejected the possibility, as they could not find any significant correlation between the two. Notwithstanding the above evidence, Sahebjamiee and colleagues conducted a study in 2015 to investigate the prevalence of human papillomavirus among the Iranian population suffering from OLP; their findings, indicating that $27.5 \%$ of the patients carry the papillomavirus, reflect a lower prevalence than that reported in a previous evaluation. The following year, Zhang et al. (2016) analyzed the viruses present in lichen sclerosus, an uncommon condition related to LP; they described the presence of the Epstein-Barr DNA virus (EBV), but were unable to detect any papillomavirus. In fact, EBV had already been associated with skin diseases years before, as Snijders and co-workers published their classical work demonstrating a strong relationship between the virus and hairy leukoplakia, a disease that causes a white corrugated lesion on the side of the tongue (Snijders et al. 1990).

The involvement of papillomavirus in OLP was confirmed by Ma and co-workers in 2016; these researchers reviewed 233 publications on the subject and concluded that two types of papillomavirus (16 and 18) were associated with the disease, in particular HPV 16. Human papillomaviruses are one of the oldest class of animal virus, as they originated around 300 million years ago, during the Paleozoic Era, while the human mucosal tropism originated ca 90 million years ago (Syrjänen 2018). These viruses can generate tumors, either benign (such as papilloma/condyloma) or malignant (such as squamous intraepithelial lesions that can further progress into squamous cell carcinoma). In addition, these DNA viruses are also related to the origin of OLP and, although originally believed to be only sexually transmitted, it is currently known that they can also be transmitted by direct mouth-to-mouth contact (Syrjänen 2018), and even by vertical transmission, from mother to child. Albeit the relevant information is still lacking, it appears that specific HPV types may be specific for the different manifestations of the OLP. Danielsson and coworkers studied in 2018 the possibility of Epstein-Barr virus (also known as human herpesvirus type 4 ) triggering OLP, by 
determining the presence of the virus in skin lesions. These authors were unable to detect any of the Epstein-Barr virusencoded small RNAs (EBER1 and EBER2; non-coding RNAs) in the biopsies they analyzed (25 corresponding to OLP and 26 to VLP), therefore concluding that this herpesvirus type 4 could not be responsible for the disease. As indicated above, de Vries et al. reported in 2007 that OLP remission is associated with a decrease in the viral load of human herpes virus type 7 , which is the reason why these DNA viruses were associated with the disease.

Human hepatitis $\mathrm{C}(\mathrm{HCV})$ is a virus that infects between three and four million people every year; Morozov and Lagaye (2018) estimate that there are 120-130 million people infected worldwide, but the association between HCV and OLP remains controversial. In 2001, Mega and colleagues carried out an immunohistochemical study of OLP, demonstrating a strong association of the disease with the hepatitis C virus, while in 2005, Elston, in his publication entitled "New and Emerging Infectious Diseases," included OLP in illnesses that could be associated with the human hepatitis $\mathrm{C}$ virus. Two publications in 2010, authored by Zhou and colleagues and Mahboobi and coworkers, reported the prevalence of HCV in patients with OLP, while 2 years later, Nagao and Sata (2012) found a similar association in a retrospective study carried out in Japan. In 2014, Carrozzo and Scally, after a thorough epidemiological study, hypothesized that a real link existed between OLP and infection by hepatitis $\mathrm{C}$ virus, with the virus triggering the disease after attracting HCV-specific T lymphocytes. However, in 2016, Song and co-workers carried out a large study on the relationship between hepatitis virus $\mathrm{C}$ and OLP, concluding that there was no apparent relationship between the two, or at least not in China, the country with the highest number of cases of the disease. Hence, the matter concerning the relationship between HCV and OLP remains to be fully elucidated, with HCV still considered associated with the disease by authors such as Eileen M. Burd, in her review in 2016, and Georgescu and colleagues in 2019.

Human cytomegalovirus is another group of DNA virus that was studied as a possible trigger of OLP; Ding et al. (2017) demonstrated that plasma levels of five human cytomegalovirus-encoded miRNAs (homv-miR-UL112-3p, homv-miR-UL22a-5p, homv-miR-UL148d, homv-miR-UL36$5 p$, and homv-miR-UL59) were significantly increased in OLP patients. Accordingly, this group of viruses is included among those that could be associated with OLP. On the other hand, Nosratzahi and colleagues reported in 2018 that both hepatitis $\mathrm{B}$ and $\mathrm{C}$ viruses are not associated with OLP disease.

\section{Other possible origins of oral lichen planus}

Recently, Congcong et al. (2019) proposed exosomal miRNAs as a possible cause of OLP. Exosomes are reticulocyte-derived extracellular structures that contain cell waste products (Johnstone et al. 1987). Exosomes have been associated with a variety of cell functions, including inflammatory responses and immunomodulation of certain tumors; Peng et al. (2019) also proposed that these structures are involved in the origin of OLP. As indicated above, T cells contribute to the disease by secreting a multitude of active biomolecules (Kurago 2016), resulting in T cell proliferation, migration, and T-mediated keratinocyte apoptosis. Exosomes are present in body fluids, such as saliva, and, as exosomes can harbor miRNAs, saliva could provide an easy and inexpensive sample to diagnose OLP. As the World Health Organization classifies this disease as an "oral potentially malignant disorder" (van der Waal 2010), the illness must be rapidly identified and treated, although currently only symptomatic therapies are available. Exosomes can enclose viral particles, and even bacteria and fungi, and help them evade the immune surveillance of the human body, which might explain why they are associated with OLP and LP.

There is currently not much information on the relationship between a particular human genotype and the susceptibility to develop OLP, although there are some indications that this might be the case. Accordingly, Al-Mohaya and co-workers studied in 2016 the effect of gene polymorphisms of T helper cell subtype Th1 and Th2 cytokines, interferon gamma, interleukin- 6 , and transforming growth factor- $\beta 1$, and concluded that a particular interferon gamma polymorphism $(874 \mathrm{~A} / \mathrm{T})$ increased the susceptibility to the disease in a Saudi cohort. The following year, Shi et al. (2017) carried out a metaanalysis of the syndrome and reported an association between interleukin polymorphisms and OLP. In 2018, Tabatabaei et al. studied a single nucleotide polymorphism in codon 72 of the tumor suppressor protein P53, encoding either arginine (Arg; CGC) or proline (Pro; CCC), and concluded that the proline allele constituted a risk factor for the progression of OLP to oral squamous cell carcinoma. In the same year, Zhou and Vieira (2018) carried out a meta-analysis of the disease and reported a positive association between a tumor necrosis factor-alpha polymorphism, a $\mathrm{G}$ to A transitional mutation at nucleotide -308, and the development of OLP. The following year, Polesello et al. (2019) reported that functional polymorphisms of the MBL2 gene, affecting either the promoter or the first exon (codons 52, 54 and 57), reduced expression of the protein and correlated with an increased risk of developing OLP; MBL2, mannose-binding lectin, is a trimeric protein with the ability to activate the complement pathway. Contrastingly, polymorphisms such as those occurring on the programmed cell death protein 1 , that once were thought to be associated with OLP, have been recently shown to have no effect on the disease (Ghapanchi et al. 2019).

In conclusion, the information currently available on OLP (and LP for that matter) does not support, at least from a strict microbiological point of view, the classification of the disease as generated by a particular microorganism (either bacterium, 
fungus, or virus), as it does not fulfill the four premises included in Koch's postulates. In fact, the current knowledge of OLP warrants inclusion of the disease within the autoimmune diseases, with the caveat that illness development may require a particular genetic background, involving particular gene point mutations (polymorphisms); this condition preferentially affects women, a common occurrence in autoimmune diseases, although whether or not the XX genetic load present in females plays a role in the disease remains to be elucidated. Progression of the disease involves colonization of the locally affected skin regions by a variety of bacteria, fungi, or viruses, probably due to epithelium damage. However, alterations in the oral microbiota, and probably also in the intestinal microbiota, resulting in dysbiosis, are likely to contribute to the development of the illness. This also means that the treatment for the disease must be carefully considered, as the effects that many of the drugs used for therapy (in particular corticoids and antibiotics) exert on the microbiota could result in worsening of the condition. The healing process for the disease should involve addressing the microbial dysbiosis and restoring the normal microbiota, not just that inhabiting the skin, but probably also the intestinal microbiota, as part of an integrated treatment of the disease.

\section{Conclusion}

In this review, we have summarized the possible origin of the OLP disease. Soon after its description, the disease was attributed to a faulty immune system of the affected, but after a variety of microorganisms, namely bacteria, fungi, and virus were described in the affected areas, it was postulated a possible microbial origin. We have reasoned in the present review, and after analyzing a number of references, that none of such microbial isolates complies with the Koch's postulates. It is our opinion therefore that until new data are obtained concerning such postulates, the disease must be considered as it was originally, as due to a deficient immune system of sick.

Acknowledgements The authors wish to express their gratitude to Dr. JLR Rama for his invaluable help with the figure of the manuscript.

Author contribution All authors have contributed equally to the manuscript.

Data availability All data presented in this paper has been obtained from public sources, journals, and so on, where any scientist may check on the information included here.

\section{Declarations}

Ethics approval and consent to participate Professor T. G. Villa, who is presenting this paper, and Professors Carmen Sieiro and Angeles Sánchez
Pérez herewith give their consent of publication in the understanding that all ethic aspects have been met. Ethics committee is not necessary for this type of papers.

Competing interests The authors declare no competing interests.

\section{References}

Adami GR, Yeung ACF, Stucki G, Kolokythas A, Sroussi HY, Cabay RJ, Kuzin I, Schwartz JL (2014) Gene expression based evidence of innate immune response activation in the epithelium with oral lichen planus. Arch Oral Biol 59:354-361

Ageitos JM, Sánchez-Pérezb A, Calo-Mata P, Villa TG (2017) Antimicrobial peptides (AMPs): ancient compounds that represent novel weapons in the fight against bacteria. Biochem Pharmacol $133: 117-138$

Akira S, Takeda K (2004) Toll-like receptor signalling. Nat Rev Immunol 4:499-511

Alastair H, Biddlestone J, McCaul J (2019) ‘Nasal flossing': a case report of nasopharyngeal stenosis due to severe erosive lichen planus and a novel therapeutic intervention. Int J Surg Case Rep 54:99-102

Allen AC, Spitz S (1945) A comparative study of the pathology of scrub typhus (tsutsugamushi disease) and other rickettsial diseases. Am J Patho. 21:603-681

Al-Mohaya MAM, Al-Otaibi L, Al-Harthi F, Al-Bakr E, Arfin M, AlAsmari A (2016) Association of genetic polymorphisms in interferon- $\gamma$, interleukin- 6 and transforming growth factor- $\beta 1$ gene with oral lichen planus susceptibility. BMC Oral Health 16:76

Auger S, Ramarao N, Faille C, Fouet A, Aymerich S, Gohar M (2009) Biofilm formation and cell surface properties among pathogenic and nonpathogenic strains of the Bacillus cereus group. Appl Environ Microbiol 75:6616-6618

Baek K, Choi Y (2018) The microbiology of oral lichen planus: is microbial infection the cause of oral lichen planus? Mol Oral Microbiol 33:22-28

Baek K, Lee J, Lee A, Lee J, Yoon H, Park HK, Chun J, Choi Y (2020) Characterization of intratissue bacterial communities and isolation of Escherichia coli from oral lichen planus lesions. Sci Rep 10:3495

Bandyopadhyay A, Behura SS, Nishat R, Dash KC, Bhuyan L, Ramachandra S (2017) Clinicopathological profile and malignant transformation in oral lichen planus: a retrospective study. J Int Soc Prev Community Dent 7:116-124

Barros HR, Paes de Almeida JR, Dinato SLM, Sementilli A, Romiti N (2013) Lichen planus pigmentosus inversus. An Bras Dermatol 88: 146-149

Barrow GI (1954) The herpes simplex virus in infantile eczema. Br Med J 1:482-486

Bauer M, Weger W, Orescovic I, Hiebaum EM, Benedicic C, Lang U, Pertl C, Pertl B (2006) Fetal microchimerism is not involved in the pathogenesis of lichen sclerosus of the vulva. Prenat Diagn 26:175178

Belay N, Mukhopadhyay B, Conway de Macario E, Galask R, Daniels L (1990) Methanogenic bacteria in human vaginal samples. J Clin Microbiol 28:1666-1668

Benitez T, Villa TG, Notario V, Garcia Acha I (1976) Studies of walls of Trichoderma viride using fluorescent brighteners. Trans Br Mycol Soc 67:485-489

Bloor BK, Seddon SV, Morgan PR (2000) Gene expression of differentiation-specific keratins (K4, K13, K1 and K10) in oral non-dysplastic keratoses and lichen planus. J Oral Pathol Med 29: 376-384 
Bornstein MM, Hakimi B, Persson GR (2008) Microbiological findings in subjects with asymptomatic oral lichen planus: a cross-sectional comparative study. J Periodontol 79:2347-2355

Bradley G (1988) Diseases of the oral mucosa. Can Fam Physician 34: 1443-1451

Brain RT (1936) Viruses in the aetiology of skin diseases. Br Med J 1: 934-936

Branch C, Whorton CM, Jones R, Pullman TN, Alving AS, Eichelberger L, Rothman S (1948) A lichen-planus-like eruption occurring during the course of chloroquine administration. J Clin Invest 27:56-59

Bray GW (1933) Epitome of current medical literature. Br Med J 2:357

Brossy J-J (1955) Pruritus ani. Proc R Soc Med 48:499-502

Burd EM (2016) Human papillomavirus laboratory testing: the changing paradigm. Clin Microbiol Rev 29:291-319

Burns JE, Clark LJ, Yeudall WA, Mitchell R, Mackenzie K, Chang SE, Parkinson EK (1994) The p53 status of cultured human premalignant oral keratinocytes. Br J Cancer 70:591-595

Byun J-S, Hong S-H, Choi JK, Jung JK, Lee HJ (2015) Diagnostic profiling of salivary exosomal microRNAs in oral lichen planus patients. Oral Dis 21:987-993

Carandina G, Bacchelli M, Virgili A, Strumia R (1984) Simonsiella filaments isolated from erosive lesions of the human oral cavity. J Clin Microbiol 19:931-933

Carrozzo M, Scally K (2014) Oral manifestations of hepatitis C virus infection. World J Gastroenterol 20:7534-7543

Carrozzo M, Uboldi de Capei M, Dametto E, Fasano ME, Arduino P, Broccoletti R, Vezza D, Rendine S, Curtoni ES, Gandolfo S (2004) Tumor necrosis factor-alpha and interferon-gamma polymorphisms contribute to susceptibility to oral lichen planus. J Investigative Dermatol 122:87-94

Chen J, Feng J, Chen X, Xu H, Zhou Z, Shen X, Bao Z, Liu W, Shen Z (2013) Immunoexpression of interleukin-22 and interleukin-23 in oral and cutaneous lichen planus lesions: a preliminary study. Mediators Inflamm 2013:801974

Cheng YS, Rees T, Jordan L, Oxford L, O’Brien J, Chen H-S, Wong D (2011) Salivary endothelin-1 potential for detecting oral cancer in patients with oral lichen planus or oral cancer in remission. Oral Oncol Oral Oncol 47:1122-1126

Cheng YS, Gould A, Kurago Z, Fantasia J, Muller S (2016) Diagnosis of oral lichen planus: a position paper of the American Academy of Oral and Maxillofacial Pathology. Oral Surg. Oral Med. Oral Pathol. Oral Radiol 122:332-354

Chitturi RT, Nirmal RM, Sunil PM, Devy AS, Reddy BVR (2014) Evaluation of ploidy status using DNA-image cytometry of exfoliated mucosal cells in oral lichen planus. J Cytol 31:131-135

Choi YS, Kim Y, Yoon H-J, Baek KJ, Alam J, Park HK, Choi Y (2016) The presence of bacteria within tissue provides insights into the pathogenesis of oral lichen planus. Sci Rep 6:29186

Congcong L, Hong H, Jiaqin W, Xinyu X, Mengyun Z, Qingzhu W (2019) Possible roles of exosomal miRNAs in the pathogenesis of oral lichen planus. Am J Transl Res 11:5313-5323

Corsi H (1947) Lichen planus in a boy aged 8 years. Proc R Soc Med 40: 477

Coussens LM, Werb Z (2002) Inflammation and cancer. Nature 420:860867

Dang J, Bian YQ, Sun JY, Chen F, Dong G, Liu Q, Wang X, Kjems J, Gao S, Wang Q (2013) MicroRNA-137 promoter methylation in oral lichen planus and oral squamous cell carcinoma. J Oral Pathol Med 42:315-321

Danielsson K, Nylander E, Sjöström M, Ebrahimi M (2018) Epstein-Barr virus is not detected in mucosal lichen planus. Med Oral Patol Oral Cir Bucal 23:e560-e563

Davidopoulou S, Theodoridis H, Nazer K, Kessopoulou E, Menexes G, Kalfas S (2014) Salivary concentration of the antimicrobial peptide LL-37 in patients with oral lichen planus. J Oral Microbiol 6. https:// doi.org/10.3402/jom.v6.26156
Day T, Otton G, Jaaback K, Weigner J, Scurry J (2018) Is vulvovaginal lichen planus associated with squamous cell carcinoma? J Low Genit Tract Dis 22:159-165

de Forest HP (1923) Leucoplakia buccalis. Ann Surg 78:474-495

de Vries HJC, Teunissen MBM, Zorgdrager F, Picavet D, Cornelissen M (2007) Lichen planus remission is associated with a decrease of human herpes virus type 7 protein expression in plasmacytoid dendritic cells. Arch Dermatol Re. 299:213-219

Ding M, Wang X, Wang C, Liu X, Zen K, Wang W, Zhang C-Y, Zhang C (2017) Distinct expression profile of HCMV encoded miRNAs in plasma from oral lichen planus patients. J Transl Med 15:133

Do TT, Phoomak C, Champattanachai V, Silsirivanit A, Chaiyarit P (2018) New evidence of connections between increased OGlcNAcylation and inflammasome in the oral mucosa of patients with oral lichen planus. Clin Exp Immunol 192:129-137

Editorial note (1969) Lichen Planus. Br Med J 4:184-185

Elston DM (2005) New and emerging infectious diseases. J Am Acad Dermatol 52:1062-1068

Emenike RKE, Olsen I (2017) Leptotrichia species in human infections II. J Oral Microbiol 9:1368848

Eppinga H, Weiland CJS, Thio HB, van der Woude CJ, Nijsten TEC, Peppelenbosch MP, Konstantinov SR (2016) Similar depletion of protective Faecalibacterium prausnitzii in psoriasis and inflammatory bowel disease, but not in hidradenitis suppurativa. J Crohns Colitis 10:1067-1075

Epstein JB, Mathias RG (1988) Oral manifestations of human immunodeficiency virus infection. Can Fam Physician 34:1773-1780

Erbagci Z, Tuncel A, Bayram N, Erkilic S, Bayram A (2006) Tuberculosis verrucosa cutis in a patient with long-standing generalized lichen planus: improvement of lichen after antitubercular polychemotherapy. J Dermatol Treat 17:314-318

Ertugrul AS, Arslan U, Dursun R, Hakki SS (2013) Periodontopathogen profile of healthy and oral lichen planus patients with gingivitis or periodontitis. Int J Oral Sci 5:92-97

Fox GH (1898) Skin diseases of children. Br Med J. September 10(Reviews):720

Fox EC, Ainsworth GC (1958) A contribution to the mycology of the mouth. Br Med J 2:826-828

Frankel A, Penrose C, Emer J (2009) Cutaneous tuberculosis: a practical case report and review for the dermatologist. J Clin Aesthet Dermatol 2:19-27

Fry L, Withers M (1968) Lichen planus: failure to cultivate viruses or mycoplasma. Br J Dermatol 80:384-386

Gammill HS, Nelson JL (2010) Naturally acquired microchimerism. Int J Dev Biol 54:531-543

Ge X, Xie H, Nguyen T, Zhao B, Xu J, Du J (2020) Renin promotes STAT4 phosphorylation to induce IL-17 production in keratinocytes of oral lichen planus. Science 23:100983

Georgescu SR, Tampa M, Mitran MI, Mitran CI, Sarbu MI, Nicolae I, Matei C, Caruntu C, Neagu M, Popa MI (2019) Potential pathogenic mechanisms involved in the association between lichen planus and hepatitis C virus infection. Exp Ther Med 17:1045-1051

Ghannoum MA, Jurevic RJ, Mukherjee PK, Cui F, Sikaroodi M, Naqvi A, Gillevet PM (2010) Characterization of the oral fungal microbiome (mycobiome) in healthy individuals. PLoS Pathog 6: e1000713

Ghapanchi J, Ghaderi H, Haghshenas MR, Jamshidi S, Rezazadeh F, Azad A, Farzin M, Derafshi R, Kalantari AH (2019) Observational molecular case-control study of genetic polymorphisms 1 in programmed cell death protein-1 in patients with oral lichen planus. Asian Pac J Cancer Prev 20:421-424

Gharabaghi MA $(2012$, 2012) Cutaneous tuberculosis caused by isoniazid-resistant Mycobacterium tuberculosis. BMJ Case Rep: bcr2012006253

Ghodsi SZ, Daneshpazhooh M, Shahi M, Nikfarjam A (2004) Lichen planus and hepatitis C: a case-control study. BMC Dermatol 4:6 
Gorouhi F, Davari P, Fazel N (2014) Cutaneous and mucosal lichen planus: a comprehensive review of clinical subtypes, risk factors, diagnosis, and prognosis. TheScientific World Journal 742826

Gupta S, Jawanda MK (2015) Oral lichen planus: an update on etiology, pathogenesis, clinical presentation, diagnosis and management. Indian J Dermatol 60:222-229

Haneke E (1983) Isolated bullous lichen planus of the nails mimicking yellow nail syndrome. Clin Exp Dermatol 8:425-428

He Y, Gong D, Shi C, Shao F, Shi J, Fei J (2017) Dysbiosis of oral buccal mucosa microbiota in patients with oral lichen planus. Oral Dis 23: 674-682

Hong H, Xia X, Yang H, Peng Q, Zheng J (2020) A pilot study: a possible implication of Candida as an etiologically endogenous pathogen for oral lichen planus. BMC Oral Health 20:72

Hongal BP, Kulkarni VV, Deshmukh RS, Joshi PS, Karande PP, Shroff AS (2015) Prevalence of fungal hyphae in potentially malignant lesions and conditions - does its occurrence play a role in epithelial dysplasia? J Oral Maxillofac Pathol 19:10-17

Horn TD, Zahurak ML, Atkins D, Solomon AR, Vogelsang GB (1997) Lichen planus-like histopathologic characteristics in the cutaneous graft-vs-host reaction. Prognostic significance independent of time course after allogeneic bone marrow transplantation. Arch Dermatol 133(8):961-965

Howell FV (1964) Oral mucous membrane lesions - pathologic features. Calif Med. 100:186-191

Irvine C (1991) 'Skin failure' - a real entity: discussion paper. J R Soc Med 84:412-413

Israr M, Mitchell D, Alam S, Dinello D, Kishel JJ, Meyers C (2010) Effect of the HIV protease inhibitor Amprenavir on the growth and differentiation of primary gingival epithelium. Antivir Ther 15:253-265

Israr M, Mitchell D, Alam S, Dinello D, Kishel JJ, Meyers C (2011) HIV protease inhibitor lopinavir/ritonavir (Kaletra) alters growth, differentiation and proliferation of primary gingival epithelium. HIV Med 12(3): $145-156$

Jacobsen MD, Duncan AD, Bain J, Johnson EM, Naglik JR, Shaw DJ, Gow NA, Odds FC (2008) Mixed Candida albicans strain populations in colonized and infected mucosal tissues. FEMS Yeast Res 8: 1334-1338

Jiang CK, Flanagan S, Ohtsuki M, Shuai K, Freedberg IM, Blumenberg M (1994) Disease-activated transcription factor: allergic reactions in human skin cause nuclear translocation of STAT-91 and induce synthesis of keratin K17. Mol Cell Biol 14:4759-4769

Johnstone RM, Adam M, Hammond JR, Orr L, Turbide C (1987) Vesicle formation during reticulocyte maturation. Association of plasma membrane activities with released vesicles (exosomes). J Biol Chem 262:9412-9420

Kaczor-Urbanowicz KE, Carreras-Presas CM, Aro K, Tu M, GarciaGodoy F, Wong DTW (2017) Saliva diagnostics - Current views and directions. Exp Biol Med (Maywood) 242:459-472

Kakabadze MZ, Paresishvili T, Karalashvili L, Chakhunashvili D, Kakabadze Z (2020) Oral microbiota and oral cancer: review. Oncol Rev 14:476

Kalia S, Dutz JP (2007) New concepts in antimalarial use and mode of action in dermatology. Dermatol Ther 20:160-174

Kawai T, Akira S (2010) The role of pattern-recognition receptors in innate immunity: update on Toll-like receptors. Nat Immunol 11: $373-384$

Kazanowska-Dygdała M, Duś I, Radwan-Oczko M (2016) The presence of Helicobacter pylori in oral cavities of patients with leukoplakia and oral lichen planus. J Appl Oral Sci 24:18-23

Kulkarni G, Sakki EP, Kumar YV, Kolimi S, Perika R, Karthik KV, Kumar KM, Kalyan VS (2016) Expression of CD1a by Langerhan's Cells in Oral Lichen Planus - A Retrospective Analysis. J Clin Diagn Res 10:ZC28-ZC31
Kundu P, Blacher E, Elinav E, Pettersson S (2017) Our gut microbiome: the evolving inner self. Cell 171:1481-1493

Kupper TS, Fuhlbrigge RC (2004) Immune surveillance in the skin: mechanisms and clinical consequences. Nat Rev Immunol 4:211222

Kurago ZB (2016) Etiology and pathogenesis of oral lichen planus: an overview. Oral Surg Oral Med Oral Pathol Oral Radiol 122:72-80

Lederer A (1919) Public health laboratory notes. Am J Public Health (N Y) 9:316-320

Lee SY, Lee E, Park YM, Hong SJ (2018) Microbiome in the gut-skin axis in atopic dermatitis. Allergy Asthma Im Emunol Res 10:354 362

Leslie-Roberts H (1922) Focal infection in relation to the etiology of skin diseases. Br Med J 1:262-264

Li N, Zhao M, Wang J, Liu Z, Diaz LA (2009) Involvement of the apoptotic mechanisms in pemphigus foliaceus autoimmune injury of the skin. J Immunol 182:711-717

Li H, Zuo J, Tang W (2018a) Phosphodiesterase-4 inhibitors for the treatment of inflammatory diseases. Front Pharmacol 9:1048

Li X, Yu C, Hu Y, Xia X, Liao Y, Zhang J, Chen H, Lu W, Zhou W, Song Z (2018b) New application of psoralen and angelicin on periodontitis with anti-bacterial, anti-inflammatory, and osteogenesis effects. Front Cell Infect Microbiol 8:178

Li C, He H, Wang J, Xia X, Zhang M, Wu Q (2019a) Possible roles of exosomal miRNAs in the pathogenesis of oral lichen planus. Am J Transl Res 11:5313-5323

Li Y, Wang K, Zhang B, Tu Q, Yao Y, Cui B, Ren B, He J, Shen X, Van Nostrand JD, Zhou J, Shi W, Xiao L, Lu C, Zhou X (2019b) Salivary mycobiome dysbiosis and its potential impact on bacteriome shifts and host immunity in oral lichen planus. Int $\mathrm{J}$ Oral Sci 11:13

Lijima W, Ohtani H, Nakayama T, Sugawara Y, Sato E, Nagura H, Yoshie O, Sasano T (2003) Infiltrating CD8+ T cells in oral lichen planus predominantly express CCR 5 and CXCR3 and carry respective chemokine ligands RANTES/CCL5 and IP-10/CXCL10 in their cytolytic granules. A potential self-recruiting mechanism. Am J Pathol 163:261-268

Loning T, Ikenberg H, Becker J, Gissman L, Hoepfner I, Zur hausen H (1985) Analysis of oral papilomas, leukoplakias and invasive carcinomas for human papillomavirus type related DNA. J Invest Derrnatol 88:417-420

Lundgren A, Suri-Payer E, Enarsson K, Svennerholm AM, Lundin BS (2003) Helicobacter pylori-specific CD4+ CD25high regulatory T cells suppress memory T-cell responses to $H$. pylori in infected individuals. Infect Immun 71:1755-1762

Ma J, Zhang J, Zhang Y, Lv T, Liu J (2016) The magnitude of the association between human papillomavirus and oral lichen planus: a meta-analysis. PLoS One 11:e0161339

Machin SE, McConnell DT, Adams JD (2010) Vaginal lichen planus: preservation of sexual function in severe disease. BMJ Case Rep 2010:bcr08.2009.2208

Mahboobi N, Agha-Hosseini F, Lankarani KB (2010) Hepatitis C virus and lichen planus: the real association. Hepat Mon 10:161-164

Maitland NJ, Cox MF, Lynas C, Prime SS, Meanwell CA, Scully C (1987) Detection of human papillomavirus DNA in biopsies of human oral tissue. Br J Cancer 56:245-250

Malekzadeh H, Robati M, Yousefimanesh H, Boroujerdnia MG, Nadripour R (2015) Salivary interferon gamma and interleukin-4 levels in patients suffering from oral lichen planus. Cell J 17:554 558

Marttila E, Uittamo J, Rusanen P, Lindqvist C, Salaspuro M, Rautemaa R (2013) Acetaldehyde production and microbial colonization in oral squamous cell carcinoma and oral lichenoid disease. Oral Surg Oral Med Oral Pathol Oral Radiol 116:61-68

Matsuoka LY (1981) Graft versus host disease. J Am Acad Dermatol 5: 595-599 
Mega H, Jiang WW, Takagi M (2001) Immunohistochemical study of oral lichen planus associated with hepatitis $\mathrm{C}$ virus infection, oral lichenoid contact sensitivity reaction and idiopathic oral lichen planus. Oral Dis 7:296-305

Mester A, Lucaciu O, Ciobanu L, Apostu D, Ilea A, Campian RS (2018) Clinical features and management of oral lichen planus (OLP) with emphasis on the management of hepatitis $\mathrm{C}$ virus (HCV)-related OLP. Bosn J Basic Med Sci 18:217-223

Mitchell JH (1935) Streptococcic infection simulating ringworm of the hands and feet. JAMA 104:1220-1225

Mitchell D, Israr M, Alam S, Kishel J, Dinello D, Meyers C (2012) Effect of HIV nucleoside reverse transcriptase inhibitor, Zidovudine, on the growth and differentiation of primary gingival epithelium. HIV Med 13:276-290

Mittal N, Shankari GSM, Palaskar S (2012) Role of angiogenesis in the pathogenesis of oral lichen planus. J Oral Maxillofac Pathol 16:4548

Miyachi M, Matsuno T, Asano K, Mataga I (2015) Anti-inflammatory effects of astaxanthin in the human gingival keratinocyte line NDUSD-1. J Clin Biochem Nutr 56:171-178

Mizuki H, Abe R, Si K, Mikami T (2017) Immunohistochemical detection of Mycoplasma salivarium in oral lichen planus tissue. J Oral Pathol Med 46:649-656

Mori Y, Yoshimura A, Ukai T, Lien E, Espevik T, Hara Y (2003) Immunohistochemical localization of Toll-like receptors 2 and 4 in gingival tissue from patients with periodontitis. Oral Microbiol Immunol 18:54-58

Morozov VA, Lagaye S (2018) Hepatitis C virus: morphogenesis, infection and therapy. World J Hepatol 10:186-212

Mostafa, Tarakji N (2015) Photodynamic therapy in treatment of oral lichen planus. J Clin Med Res 7:393-399

Murakami Y, Machino M, Fujisawa S (2012) Porphyromonas gingivalis fimbria-induced expression of inflammatory cytokines and cyclooxygenase- 2 in mouse macrophages and its inhibition by the bioactive compounds fibronectin and melatonin. ISRN Dent 2012: 350859

Nagao Y, Sata M (2012) A retrospective case-control study of hepatitis C virus infection and oral lichen planus in Japan: association study with mutations in the core and NS5A region of hepatitis $\mathrm{C}$ virus. BMC Gastroenterol 12:31

Nagao Y, Kimura K, Kawahigashi Y, Sata M (2016) Successful treatment of hepatitis $\mathrm{C}$ virus-associated oral lichen planus by interferon-free therapy with direct-acting antivirals. Clin Transl Gastroenterol 7: e179

Nagao Y, Nakasone K, Maeshiro T, Nishida N, Kimura K, Kawahigashi Y, Tanaka Y, Sata M (2017) Successful treatment of oral lichen planus with direct-acting antiviral agents after liver transplantation for hepatitis $\mathrm{C}$ virus-associated hepatocellular carcinoma. Case Rep Gastroenterol 11:701-710

Negrato CA, Tarzia O (2010) Buccal alterations in diabetes mellitus. Diabetol Metab Syndr 2:3

Nosratzahi T, Raiesi M, Shahryari B (2018) Lack of association between oral lichen planus and hepatitis $\mathrm{B}$ and $\mathrm{C}$ virus infection - a report from southeast Iran. Asian Pac J Cancer Prev 19:1633-1637

Odds FC, Auger P, Krogh P, Neely AN, Segal E (1989) Biotyping of Candida albicans: results of an international collaborative survey. $\mathrm{J}$ Clin Microbiol 27:1506-1509

Panja G (1925) Lichen spinulosus. Ind Med Gaz 60:467-468

Peacock ME, Arce RM, Cutler CW (2017) Periodontal and other oral manifestations of immunodeficiency diseases. Oral Dis 23:866-888

Peng Q, Zhang J, Zhou G (2019) Circulating exosomes regulate T-cellmediated inflammatory response in oral lichen planus. J Oral Pathol Med 48:143-150

Pereira JS, Monteiro BV, Nonaka CF, Silveira EJ, Miguel MC (2012) FoxP3+ T regulatory cells in oral lichen planus and its correlation with the distinct clinical appearance of the lesions. Int J Exp Pathol 93:287-294

Pock L, Jelínková L, Drlík L, Abrhámová S, Vojtechovská S, Sezemská D, Borodácová I, Hercogová J (2001) Lichen planus pigmentosusinversus. J Eur Acad Dermatol Venereol 15:452-454

Poindexter HA (1947) Observations on the etiology and treatment of lichen planus atypicus and "jungle rot". J Natl Med Assoc 39: $146-150$

Polesello V, Segat L, Biasotto M, Ottaviani G, Gobbo M, Di Lenarda R, Crovella S, Zupin L (2019) Mannose-binding lectin 2 (MBL2) combined genotypes deficiency is associated with susceptibility for oral lichen planus. Genet Mol Biol 42:9-14

Punjabi V, Patel S, Pathak J, Swain N (2020) Comparative evaluation of staining efficacy of calcofluor white and acridine orange for detection of Candida species using fluorescence microscopy - A prospective microbiological study. J Oral Maxillofac Pathol 24:81-86

Rao UKM, Thavarajah R, Joshua E, Ranganathan K (2018) Loss of heterozygosity as a marker to predict progression of oral epithelial dysplasia to oral squamous cell carcinoma. J Oral Maxillofac Pathol 22:155-160

Razavi SM, Ghalayani P, Salehi MR, Attarzadeh H, Shahmoradi M (2009) Human papilloma virus as a possible factor in the pathogenesis of oral lichen planus. Dent Res J 6:82-86

Ren L, Leung WK, Darveau RP, Jin L (2005) The expression profile of lipopolysaccharide-binding protein, membrane-bound CD14, and toll-like receptors 2 and 4 in chronic periodontitis. J Periodontol 76:1950-1959

Riddell JR (1928) Ultra-violet light therapy. Glasgow Med J 110:76-99

Roopashree MR, Gondhalekar RV, Shashikanth MC, George J, Thippeswamy SH, Shukla A (2010) Pathogenesis of oral lichen planus - a review. J Oral Pathol \& Medicine 39:729-734

Sahebjamiee M, Sand L, Karimi S, Biettolahi JM, Jabalameli F, Jalouli J (2015) Prevalence of human papillomavirus in oral lichen planus in an Iranian cohort. J Oral Maxillofac Pathol 19:170-174

Sahin M, Bilgili SG, Simsek H, Akdag S, Akyol A, Gumrukcuoglu HA, Yaman M, Bayram Y, Karadag AS (2013) Increased P-wave dispersion in patients with newly diagnosed lichen planus. Clinics (Sao Paulo) 68:846-850

Salem A, Almahmoudi R, Hagström J, Stark H, Nordström D, Salo T, Eklund KK (2019) Human $\beta$-defensin 2 expression in oral epithelium: potential therapeutic targets in oral lichen planus. Int J Mol Sci 20:1780

Samman PD (1969) Lichen planus: a dermatological centenary. Br J Dermatol 81:306-307

Sánchez-Siles M, Aliaga-Sánchez A, Medina S, Adoamnei E, FernándezRuiz JA, Pelegrín-Hernández JP, Corno-Caparrós A, Rosa-Salazar V, Camacho-Alonso F (2019) Genotyping of the C>T allele of rs 16906252, predictor of O16-methylguanine-DNA methyltransferase (MGMT) promoter methylation status, in erosive atrophic lesions of oral lichen planus. Int J Dermatol 58:1078-1082

Sato Y, Takenaka R, Matsumi A, Takei K, Okanoue S, Yasutomi E, Kawai D, Takemoto K, Tsugeno H, Miyake T, Fujiki S (2018) A Japanese case of esophageal lichen planus that was successfully treated with systemic corticosteroids. Intern Med 57:25-29

Scardina GA, Messina P (2012) Good oral health and diet. J Biomed Biotechnol 2012:720692

Schmidt TSB, Raes J, Bork P (2018) The human gut microbiome: from association to modulation. Cell 172:1198-1215

Schwartz L (1933) Industrial dermatitis in the United States. Am J Public Health Nations Health 23:1049-1054

Seoane J, Ramírez JR, Romero MA, Varela-Centelles P, Garcia-Pola MJ (2004) Expression of heat shock protein (HSP70) in oral lichen planus and non-dysplastic oral leukoplakia. Clin Otolaryngol Allied Sci 29:191-196 
Sharma R, Sircar K, Singh S, Rastogi V (2011) Role of mast cells in pathogenesis of oral lichen planus. J Oral Maxillofac Pathol 15: 267-271

Shetty RR, Burde KN, Guttal KS (2016) The efficacy of topical hyaluronic acid $0.2 \%$ in the management of symptomatic oral lichen planus. J Clin Diagn Res 10:ZC46-ZC50

Shi Q, Zhang T, Huo N, Huang Y, Xu J, Liu H (2017) Association between polymorphisms in interleukins and oral lichen planus: a meta-analysis. Medicine (Baltimore) 96:e6314

Siponen M, Kauppila JH, Soini Y, Salo T (2012) TLR4 and TLR9 are induced in oral lichen planus. J Oral Pathol Med 41:741-747

Slots J, Slots H (2011) Bacterial and viral pathogens in saliva: disease relationship and infectious risk. Periodontol 55:48-69

Snijders PJ, Schulten EA, Mullink H, ten Kate RW, Jiwa M, van der Waal I, Meijer CJ, Walboomers JM (1990) Detection of human papillomavirus and Epstein-Barr virus DNA sequences in oral mucosa of HIV-infected patients by the polymerase chain reaction. Am J Pathol 137:659-666

Song J, Zhang Z, Ji X, Su S, Liu X, Xu S, Han Y, Mu D, Liu H (2016) Lack of evidence of hepatitis in patients with oral lichen planus in China: a case control study. Med Oral Patol Oral Cir Bucal 21:e161-e168

Souter JC (1937) A clinical note on fungus infection of the skin of the feet. Proc R Soc Med. 30:1107-1116

Stipcevic T, Piljac T, Isseroff RR (2005) Di-rhamnolipid from Pseudomonas aeruginosa displays differential effects on human keratinocyte and fibroblast cultures. J Dermatol Sci 40:141-143

Sugawara Y, Uehara A, Fujimoto Y, Kusumoto S, Fukase K, Shibata K, Sugawara S, Sasano T, Takada H (2006) Toll-like receptors, NOD1, and NOD2 in oral epithelial cells. J Dent Res 85:524-529

Syrjänen S (2018) Oral manifestations of human papillomavirus infections. Eur J Oral Sci 126:49-66

Tabatabaei SH, Sheikhha MH, Karbasi MHA, Zarmehi S, Hoseini M (2018) Evaluation of polymorphism of P53 protein codon 72 in oral lichen planus by PCR technique. J Dent Res Dent Clin Dent Prospects 12:245-251

Talungchit S, Buajeeb W, Lerdtripop C, Surarit R, Chairatvit K, Roytrakul S, Kobayashi H, Izumi Y, Khovidhunkit SP (2018) Putative salivary protein biomarkers for the diagnosis of oral lichen planus: a case-control study. BMC Oral Health 18:42

Tampa M, Caruntu C, Mitran M, Mitran C, Sarbu I, Rusu L, Matei C, Constantin C, Neagu M, Georgescu S (2018) Markers of oral lichen planus malignant transformation. Dis Markers 2018:1959506

Tan Y, Zhang J, Du G, Lu R, Chen G, Zhou G (2016) Altered autophagyassociated genes expression in T cells of oral lichen planus correlated with clinical features. Mediators Inflamm 2016:4867368

Tang L, Zhou X-D, Wang Q, Zhang L, Wang Y, Li X-Y, Huang D-M (2011) Expression of TRAF6 and pro-inflammatory cytokines through activation of TLR2, TLR4, NOD1, and NOD2 in human periodontal ligament fibroblasts. Arch Oral Biol 56:1064-1072

Tavaria M, Gabriele T, Kola I, Anderson RL (1996) A hitchhiker's guide to the human Hsp70 family. Cell Stress Chaperones 1:23-28

Tomo S, Santos IS, de Queiroz S, Bernabé D, Simonato L, Miyahara G (2017) Uncommon oral manifestation of lichen sclerosus: critical analysis of cases reported from 1957 to 2016. Med Oral Patol Oral Cir Bucal 22:e410-e416

Tyagi N, Shetty DC, Urs AB (2012) Altered expression of HSP70 in oral lichen planus. J Oral Maxillofac Pathol. 16:189-194

Uehara A, Takada H (2008) Synergism between TLRs and NOD1/2 in oral epithelial cells. J Dent Res. 87:682-686

Unna PG (1896) The histopathology of the diseases of the skin. William F. Clay, Edinburgh

van der Waal I (2010) Potentially malignant disorders of the oral and oropharyngeal mucosa; present concepts of management. Oral Oncol. 46:423-425
Villa TG, Sánchez-Pérez A, Viñas M (2016) The biological fight against pathogenic bacteria and protozoa. In: Villa TG, Viñas M (eds) New weapons to control bacterial growth. Springer Nature, Switzerland, pp 509-556

Wagner G, Rose C, Sachse MM (2013) Clinical variants of lichen planus. J der Deuts Dermatolog Gesellschaft 11:309-319

Walsh LJ, Davis MF, Xu LJ, Savage NW (1995) Relationship between mast cell degranulation and inflammation in the oral cavity. J Oral Pathol Med 24:266-272

Wang J, Ge B, Li Z, Guan F, Li F (2016a) Structural analysis and immunoregulation activity comparison of five polysaccharides from Angelica sinensis. Carbohydr Polym. 140:6-12

Wang K, Lu W, Tu Q, Ge Y, He J, Zhou Y, Gou Y, Van Nostrand JD, Qin Y, Li J, Zhou J, Li Y, Xiao L, Zhou X (2016b) Preliminary analysis of salivary microbiome and their potential roles in oral lichen planus. Sci Rep. 6:22943

Wang L, Yang Y, Xiong X, Yu T, Wang X, Meng W, Wang H, Luo G, Ge L (2018) Oral lichen-planus-associated fibroblasts acquire myofibroblast characteristics and secrete pro-inflammatory cytokines in response to Porphyromonas gingivalis lipopolysaccharide stimulation. BMC Oral Health 18:197

Wang J, Chen G, Shi T, Wang Y, Guan C (2019) Possible treatment for cutaneous lichen planus: an in vitro anti-inflammatory role of Angelica polysaccharide in human keratinocytes HaCaT. Int J Immunopathol Pharmacol. 33:2058738418821837

Watanabe T, Matsuura M, Seto K (1986) Enumeration, isolation, and species identification of mycoplasmas in saliva sampled from the normal and pathological human oral cavity and antibody response to an oral mycoplasma (Mycoplasma salivarium). J Clin Microbiol 23: $1034-1038$

Wilson E (1869) Lectures on cutaneous medicine and diseases of the skin: X. On ekzema. J Cutan Med 3:105-120

Xavier GM, S'a ARD, Guimaraes ALS, Silva TAD, Gomez RS (2007) Investigation of functional gene polymorphisms interleukin- $1 \beta$, interleukin-6, interleukin-10 and tumor necrosis factor in individuals with oral lichen planus. J Oral Pathol Med 36:476-481

Xian P, Xuedong Z, Xin X, Yuqing L, Yan L, Jiyao L, Xiaoquan S, Shi H, Jian X, Ga L (2018) The Oral Microbiome Bank of China. Int J Oral Sci 10:16

Yang X, Hegde VL, Rao R, Zhang J, Nagarkatti PS, Nagarkatti M (2014) Histone modifications are associated with $\Delta$ 9-tetrahydrocannabinol-mediated alterations in antigen-specific T cell responses. J Biol Chem 289:18707-18718

Yu FY, Wang QQ, Li M, Cheng YH, Cheng YL, Zhou Y, Yang X, Zhang F, Ge X, Zhao B, Ren XY (2020) Dysbiosis of saliva microbiome in patients with oral lichen planus. BMC Microbiol 20:75

Zhang J, Zhou G (2012) Green tea consumption: an alternative approach to managing oral lichen planus. Inflamm Res 61:535-539

Zhang Y, Fu Q, Zhang X (2016) The presence of human papillomavirus and Epstein-Barr virus in male Chinese lichen sclerosus patients: a single center study. Asian J Androl 18:650-653

Zhou Y, Vieira AR (2018) Association between TNF $\alpha$ - 308 G/A polymorphism and oral lichen planus (OLP): a meta-analysis. J Appl Oral Sci 26:e20170184

Zhou Y, Jiang L, Liu J, Zeng X, Chen Q (2010) The prevalence of hepatitis $\mathrm{C}$ virus infection in oral lichen planus in an ethnic Chinese cohort of 232 patients. Int J Oral Sci 2:90-97

Zunt SL, Burton LV, Goldblatt LI, Dobbins EE, Srinivasan M (2009) Soluble forms of Toll-like receptor 4 are present in human saliva and modulate tumour necrosis factor- $\alpha$ secretion by macrophage-like cells. Clin Exp Immunol 156:285-293

Publisher's note Springer Nature remains neutral with regard to jurisdictional claims in published maps and institutional affiliations. 